Çukurova Üniversitesi Mühendislik Mimarlık Fakültesi Dergisi, 31(ÖS 2), ss. ÖS 1-ÖS 7, Ekim 2016

Çukurova University Journal of the Faculty of Engineering and Architecture, 31(SI 2), pp. SI 1-SI 7, October 2016

\title{
Titanyum Esaslı Kilitleme Plakalarının Toz Enjeksiyon Kalıplama Süreci
}

\author{
Levent URTEKİN ${ }^{* 1}$ \\ ${ }^{1}$ Ahi Evran Üniversitesi, Mühendislik Mimarlık Fakültesi, Makine Mühendisliği Bölümü, \\ Kırşehir
}

Geliş tarihi: 08.08.2016 Kabul tarihi: 13.10 .2016

\section{$\ddot{O} z$}

Titanyum alaşımı otomotiv, medikal ve uçak/uzay sanayinde kullanılan önemli bir malzemedir. Titanyum alaşımlarının klasik yöntemlerle işlenmesi oldukça zordur. Özellikle karmaşık geometrilerin üretilmesi sırasında tolerans değerlerinin yakalanması imalatçıları farklı yöntemler geliştirmeye yöneltmiştir. Bu kapsamda titanyum esaslı kilitleme plakalarının metal enjeksiyon kalıplama ile üretilmesi çalışmalarına başlanılmıştır. Metal enjeksiyon kalıplama yöntemi hassas tolerans, karmaşık şekil ve seri üretim için vazgeçilmez bir imalat sürecidir. Bu çalışmada; titanyum alaşım tozları ile elde edilen besleme stoklarının kalıp içerisindeki akış parametreleri incelenmiştir. Akış parametreleri Autodesk Moldflow Simülasyon programıyla denenmiş̧tir. Silindir sıcaklığının $190-210^{\circ} \mathrm{C}$ arasında değiştiği tespit edilmiştir. Enjeksiyon basınc1 kalıp ve yolluk geometrisine göre değiş̧iklik gösterdiği belirlenmiştir. Ütüleme basıncı ise enjeksiyon basıncının \%30-60'ı aralığında olduğu analiz edilmiştir. Yapılan analizler neticesinde titanyum esaslı kilitleme plakalarının metal enjeksiyon kalıplama yöntemiyle üretileceğine karar verilmiştir.

Anahtar Kelimeler: Titanyum, Metal enjeksiyon kalıplama, İmplant

\section{Powder Injection Molding Process of Titanium Based Locking Plate}

\begin{abstract}
Titanium alloy is important material which is used for automotive, medical and aircraft/aerospace industry. It is very difficult to machine titanium alloys by conventional methods. The obtaining tolerance values during especially the production of complex geometry have led to manufacturers to develop different methods. In this content, the production of titanium based locking plate was initiated by metal injection molding method. The metal injection molding method is an indispensable manufacturing process for the sensitive tolerance, the serial manufacturing and the production of complex shapes. In this study, flow parameters inside the mold of the feedstocks made from the titanium alloy powder was investigated. The flow parameters were examined by Autodesk Moldflow simulation program. The cylinder temperature was found to be varied from 190 to $210^{\circ} \mathrm{C}$. It was determined that the injection pressure was varied depending on the mold and allowances geometry. The holding pressure was found to be $30-60 \%$ of the injection pressure. Based on the performed analyses, titanium based locking plates could be produced by metal injection molding method.
\end{abstract}

Keywords: Titanium, Metal injection molding, Implant

\footnotetext{
*Sorumlu yazar (Corresponding author): Levent URTEKIN, levent.urtekin@ahievran.edu.tr
} 


\section{GIiRIŞ}

Toz Enjeksiyon Kalıplama (TEK), 1920'li yıllardan beri gelişmekte olan bir imalat yöntemidir [1]. İkinci Dünya Savaşı sıralarında uranyum zenginleştirmek için kullanılan tüpler organik bağlayıcılar ile nikel tozları kullanılarak elde edilmiştir [2]. 1950'lerin içinde Sovyetler Birliğinde parafin bağlayıcı kullanılarak seramikler elde edilmiştir [3]. 1950'lerden sonra bir çok karbür ve seramik temelli karmaşık şekilli parçaların (epoksi, parafin yada selüloz bağlayıcılar kullanılarak) üretiminde TEK kullanılmıştır [4]. Endüstriyel olarak ise 1970'lerde Kaliforniya'da Parmatech firması tarafından ilk defa kullanılmıştır [5]. TEK işlemi plastik enjeksiyon ve toz metalurjisinin birleşmesiyle ortaya çıkmıştır. 1979'lara gelindiğinde, uçakta kullanılan TEK ile üretilmiş vida tıkacı ve niyobyum alaşımlı roket parçasının ödül alması gelişmeleri daha da hızlandırmıştır [2]. 1980'lerin başında ise seramik isı makinası parçaları TEK ile yapılmıştır [4]. 1998'de ise, TEK ürünü helisel dişli ve cerrahide kullanılan kavisli makas MPIF (Metal Powder Industries Federation$\mathrm{ABD})$ tarafından ödüllendirilmiştir.

Toz Enjeksiyon Kalıplama (TEK) işleminde reoloji çalışmasından başlayarak, karıştırma, taneleme, kalıplama, bağlayıcı giderme ve sinterleme aşamasına kadar her aşamanın kontrollü yapılması ve ürün kalitesini artırmak için birden çok parametrenin eş zamanlı uygulanması oldukça önemlidir [5-8]. Ti alaşımı enjeksiyon kalıplama sırasında; eksik dolum, çarpılma, mikro gözenek, çatlak, gözenek ve boşluk, kaynak çizgi hatası, baskı sırasında kırılma, itici pim izleri, kalıba yapışma, ayrışma, kabuk ve katmanlaşma, düzgün olmayan yüzey, pürüzlülük gibi hatalar oluşmaktadır. Hataların bir çoğu reolojik özellikten, kalıplama yani enjeksiyon sırasından yada bağlayıcı giderme sırasında oluşmaktadır. $\mathrm{Bu}$ hataları minimize etmek için ortaya çıkmıştır.
Titanyum alaşımlarının işlenmesinde gerekli olan kesme kuvveti makine çeliklerinin ihtiyaç duyduğu kesme kuvvetinden biraz daha yüksektir. Eşit sertliklere sahip olmasına rağmen bu alaşımların sahip olduğu metalurjik özellikler onları işlemede güçlük çıkarmaktadır. Beta alaşımlar en zor işlenen titanyum alaşımlarıdır. İşleme şartları özellikle özel bir alaşım kompozisyonu ve isleme sırası için seçilirse işlenebilirliğin gerçekçi üretim oranları kabul edilebilir maliyet düzeyinde elde edilebilir. Özellikle taşlama sırasında, yüzey bütünlüğündeki düzensizlikleri engellemek için gerekli çalışmaların yapılması Titanyum alaşımları için gerekmektedir, aksi takdirde yorulma gibi mekanik davranışlarda dramatik kayıplar oluşabilmektedir. Bugüne kadar yüksek hızda isleme gibi tekniklerle titanyum islemede gözle görülebilir gelişmeler olmamıştır. Yeni takım malzemelerinin geliştirilmesinin gerekliliği ortaya çıkmıştır [9-11]. Titanyum çeliğe göre nispeten daha düşük elastikiyet modülüne sahiptir dolayısıyla esnekliği çeliğe göre daha azdır. Ağır talaş kaldırma işlemleri için daha güçlü takımlara ihtiyaç duymaktadır. Takımdaki basınç nedeniyle, takımda sürtünme, tırlama ve tolerans problemleri gibi problemler oluşmaktadır. Titanyum alaşımlarının işlenmesi sırasında oluşan yukarıda belirtilen durumlar titanyum alaşımlarını işlenebilirliği güç malzemeler sınıfına sokmaktadır. Ti-6Al-4V vidalı kemik implantlarının işlenmesindeki zorluklar ve hem kalçada hem de bilekte yoğun olarak kullanılması bu parçanın seri üretimini gerektirmektedir. Bu tip malzemelerin klasik imalat yöntemlerinden farklı olarak lazer yada tel erozyon gibi ileri imalat yöntemleriyle işlendikleri bilinmektedir.

Titanyum alaşımı otomotiv, medikal ve uçak/uzay sanayinde kullanılan önemli bir malzemedir. Titanyum alaşımlarının klasik yöntemlerle işlenmesi oldukça zordur. Özellikle karmaşık geometrilerin üretilmesi sırasinda tolerans değerlerinin yakalanması imalatçıları farklı yöntemler geliştirmeye yöneltmiştir. Bu kapsamda Titanyum esaslı kilitleme plakalarının metal enjeksiyon kalıplama ile üretilmesi çalışmalarına başlanılmıştır. 


\section{MATERYAL VE METOT}

Toz Enjeksiyon Kalıplama (metal ve seramik) için toz boyutu ve formu önemli bir parametredir. Özellikle metaller için ortalama toz boyutu 20 mikron altı küresel tozlar yüksek paketleme yoğunluğu vermektedir. (Seramikler için toz boyutu 10 mikron altı istenmektedir) Toz boyut dağılımın da paketleme yoğunluğa etkisi bilinmekte olup sinterleme öncesi elde edilen paketleme yoğunluğunun son parçadaki yoğunluğu etkilediği önemli bir literatür bilgisidir. Yoğunluğu yüksek istenen toz metal parçalarda küresel toz şekli istenmektedir.

Dumlupınar Üniversitesi İleri Teknolojiler ve Tasarım Merkezinde yapılan analizler neticesinde ortalama toz boyutu ve toz boyut dağılımı, analizleri yapılarak Ti-6Al-4V malzemesinin Metal Enjeksiyon Kalıplama için uygunluğu belirlenmiştir. Analizler neticesinde ortalama toz boyutunun 13,4 mikron civarında olduğu ve küresel olduğu görülmüştür. Çizelge 1'de ise EDX sonucu elde edilen element analiz değerleri ağırlık ve atomik olarak verilmiştir. Şekil 1'de ise kullanılan tozların SEM görüntüsü verilmiştir.

Çizelge 1. Element analiz değerleri

\begin{tabular}{|l|c|c|}
\hline Element & A ğırlı \% & Atomik \% \\
\hline AlK & 5,67 & 9,67 \\
\hline TiK & 89,61 & 86,07 \\
\hline VK & 4,72 & 4,26 \\
\hline
\end{tabular}

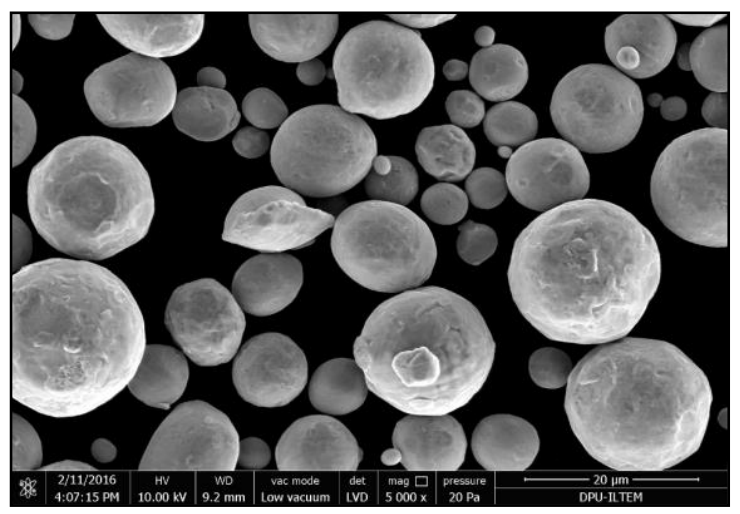

Şekil 1. Ti-6Al-4V tozunun SEM görüntüsü

\section{DENEYSEL ÇALIŞMALAR VE SIMÜLASYON}

\subsection{Reoloji Deneyi}

Metal Enjeksiyon Kalıplama yönteminin mutfağını oluşturan süreç reoloji çalışmasıdır. Metal tozu ve bağlayıcılardan oluşan karışımların granül haline getirilmesi ve Kılcal reometre (Şekil 2) adı verilen basit bir ektrusderden geçirilmesi ile bağlayıcı ve metal tozu karışımlarının (besleme stoku) akış özellikleri hakkında fikir edinilmektedir. Bağlayıcı ile metal toz karışım oranlarının belirlendiği reoloji çalışması granüllemede, kalıplamada, bağlayıcı gidermede ve sinterlemede etkili bir parametredir. Akış tipinin psödo-plastik olması (yani kayma hızı artıkça viskozitenin azalması), viskozitenin 1000 pa.s altında seyretmesi, erime akış indeksi tayini (10 gr/dk akan gram miktarı) enjeksiyon kalıplama sıcaklığının belirlenmesi reoloji çalışmalarıyla belirlenir. Şekil 2'de reoloji parametrelerinin incelendiği kılcal reometre görüntüsü verilmiştir.

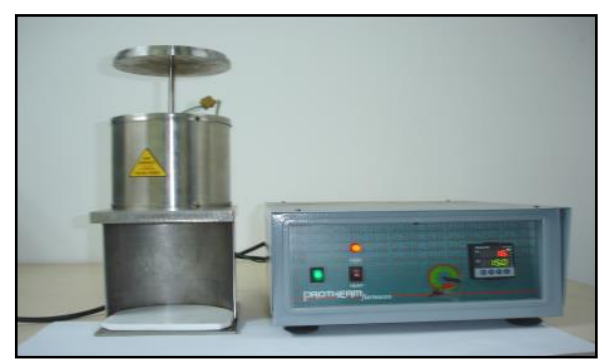

Şekil 2. Deneylerde kullanılan kılcal reometre

Kilcal reometre deneyi, Dumlupınar Üniversitesi Makina Mühendisliği Toz Metalurjisi laboratuvarında bulunan cihaz ile gerçekleştirilmiştir. 13,4 mikron Ti-6Al-4V tozları ile hazırlanan besleme stoklarının kılcal reometre denemeleri, ASTM D1238 - ASTM D3835 [12-13] standartlarına uygun olarak yapılmıştır. Elde edilen besleme stoku k1lcal reometreden geçirilerek, değişen kayma gerilmelerinde viskozitesi ve kayma hızı belirlenmiştir. Reolojik çalışmalarda kullanılan kılcal reomtrenin silindir uzunluğu $115 \mathrm{~mm}$, iç çap1 $10 \mathrm{~mm}$ 'dir. Silindir boyunca çalışabilen pistonun boyu 6,35 mm'dir. Kalıp $8 \mathrm{~mm}$ uzunluğunda ve $2 \mathrm{~mm}$ çapındadır. Besleme 
stoğu tane haline getirildikten sonra, cihaz temizlenmiştir. Deneylere başlamadan önce silindir ve piston sicaklığı $15 \mathrm{dk}$ süre ile $80-260 \pm 0,5^{\circ} \mathrm{C}^{\prime}$ de tutulmuştur, deney sirasında da bu sıcaklık aralığının değişmezliği sağlanmıştır. Silindir, ağırlığı bilinen besleme stoğu ile doldurulmuş ve üzerinde yük bulunmayan piston, silindir üstünden içeri doğru sokulmuştur.

\subsection{Akıș Simülasyon Çalıșmaları}

Ahi Evran Üniversitesi Araştırma Hastanesi Ortopedi Bölümü ile görüşülmüş en çok kullanılan Ti esaslı kilitleme plakası temin edilmiştir. Tersine mühendislik yöntemi ile vidalı parçanın tüm detayları ve tasarımı yapılmıştır. Eksik kalan ve taranamayan kısımlar Solidworks programı kullanılarak parçanın katı modeli çıkarılmıştır. Tasarım kalıp simülasyonu için hazır hale getirilmiştir. İlgili tasarımlar Şekil 3'de verilmiştir.

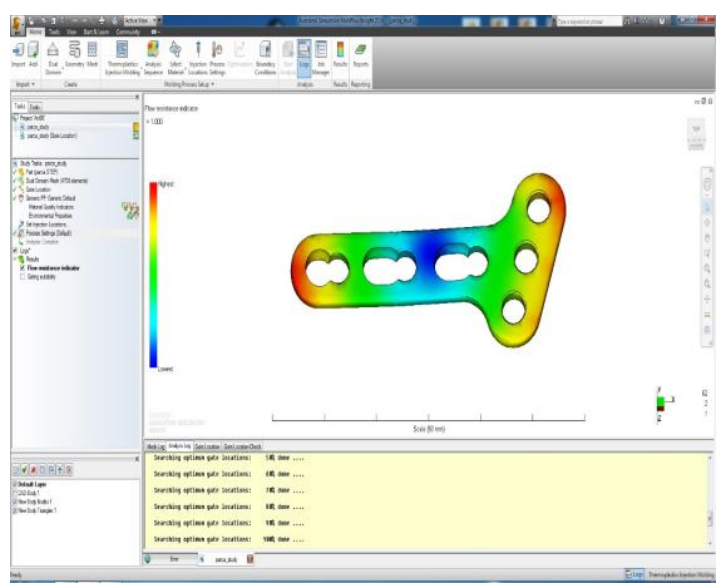

Şekil 3. Tasarlanmış Ti esaslı kilitleme plakası

Solidworks ile çizilen kilitleme plakası Autodesk Moldflow simülasyon programına import edilmiştir. Tasarımdan dolayı oluşabilecek boşluk kontrolu için yüzey kontrolü yapılmıştır. Yüzey kontrolü için kilitleme plakası parça yüzey meshlemesine tabi tutulmuştur. Mesh analizlerinde 3D meshleme yöntemi tercih edilmiştir. 3D meshleme yapıldıktan sonra en iyi yolluk ve giriş analizleri yapılmıştır. Tek enjeksiyon girişi seçilmiştir. İki gözlü kalıp seçildiğinden her parçanın stabil olması için simetrik yerleştirilmiştir. Kalıba uygun basit yolluk seçilmiş ve tıkanmalar minimize edilmiştir. Yolluklardan kaynaklanan 1S1 kayıpları önlenmiştir. Soğutma kanalları çizilmeden önce dolum prosesi incelenmiş oluşabilecek hava boşlu yada dolmama sorunu incelenmiştir. Bunlara göre erime sıcaklığı, ütüleme basıncı değerleri girilmiştir. Soğutma kanalları geometriye uygun seçilmiştir. Hatalardan kaçınmak için (çarpılma, eksik dolum vb) gerçeğe çok yakın değerler seçilmiştir.

\section{SONUCLAR}

\subsection{Reoloji Sonuçları}

Ti-6Al-4V alaşımı ile PW/PE/SA esaslı bağlayıcı sistemi ile elde edilen besleme stoku (BTi) ile yapılan reoloji çalışmalarında hacimce \%47-57 oranında toz yüklemesi yapılmıştır. Sıcaklık değişimi $180-220^{\circ} \mathrm{C}$ arasında değişmiştir. Erime akış indeksi 300-1005 (gr/10 dk) arasında değişmiştir. B1 besleme stokuna göre metal enjeskiyon kalıplama için daha uygun reolojik verilere sahiptir. Viskozite değerleri ise 80-1100 pa.sn arasında değişmektedir. Toz yüklemesinin \%57'e kadar çıktığı BTi besleme stoku metal enjeksiyon kalıplama için uygun olduğu görülmüştür.

Akış tipinin newtoniyen olmayan akış ve psöydoplastik olduğu görülmüştür. Viskozitenin 100-1000 pa.sn altında seyretmesi besleme stoklarından istenen bir durumdur. Düşük viskozitelerde püskürme yüksek viskozitelerde ise kalıbı doldurmama ve tıkanma gibi hadiseler yaşanmaktadır. Besleme stoklarının üç ana bağlayıcıdan oluşur; ana bağlayıcı, iskelet bağlayıcı ve yağlayıcıdır. Literatür çalışmalarında (steatit, alümina, alüminyum, paslanmaz çelik) besleme stoklarının iskelet bağlayıcı ile hemen hemen aynı özellikle taşıdığı söylenebilir. Bu kapsamda BTi besleme stoğunun iskelet bağlayıcısı PE ile uyumlu olduğu söylenebilir. $\mathrm{Bu}$ uyumluluk termal analiz çalışmalarında da ortaya çıkmıştır.

Şekil 4 ve 5'de erime akış indeksi-sıcaklık ve viskozite-sıcaklık değişimleri verilmiştir. 


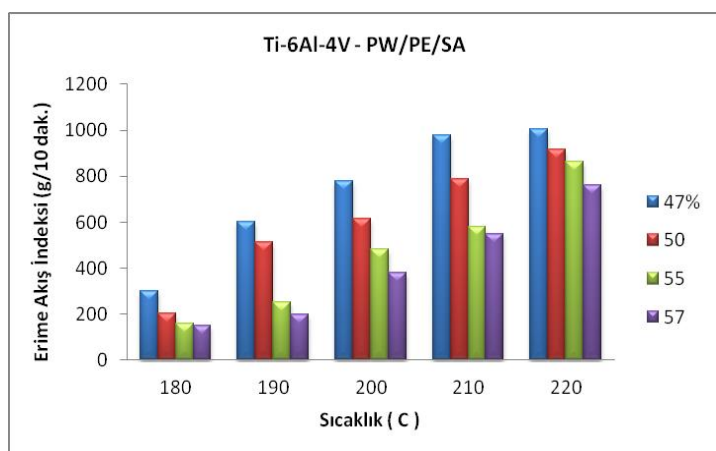

Şekil 4. Erime akış indeksi-sıcaklık değişimi

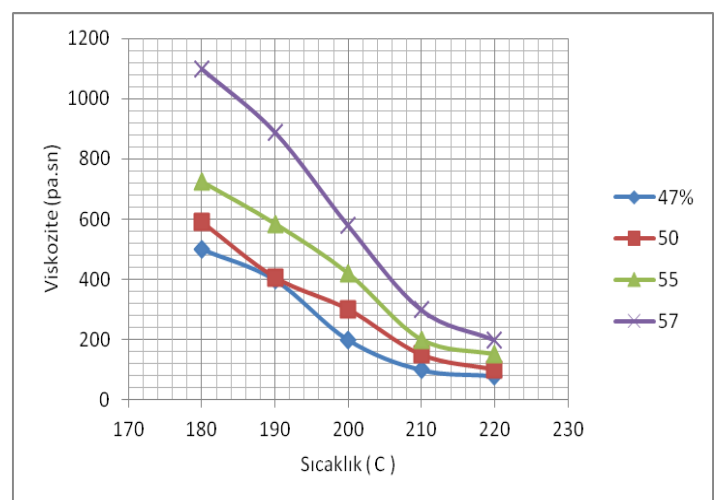

Şekil 5. Viskozite-sıcaklık değişimi

Besleme stok analizlerinin termal özellikleri birçok amaç için yapılmaktadır. Bunlardan en önemlisi akış sıcaklıklarının belirlenmesi, bağlayıcı giderme sıcaklıklarının tayini, bağlayıcı giderme hızlarının ve bağlayıcı giderme ortamının belirlenmesi olarak sıralanabilir. Bu kapsamda BTi besleme stoku için DTA/TGA analizleri yapılmış ve aşağıda veriler elde edilmiştir.

Şekil 6'da görüldüğü gibi BTi besleme stokları için TGA/DTA analizleri verilmiştir. BTi besleme stoku incelendiğinde $220^{\circ} \mathrm{C}$ 'den sonra kütle kaybı başlamış ve malzeme maksimum bozulma sicaklığı $371,5^{\circ} \mathrm{C}$ sicaklığında ve $475^{\circ} \mathrm{C}$ sicaklığa kadar bozulma devam etmiştir.

PW, PE ve SA bozulma başlangıç sıcaklıklarıyla grafikteki değerler uyumludur. Kademeli sinterlemenin önemli bir adımı olan 1sıl bağlayıcı giderme için ssıl analizler faydalı bir metottur. Şekil 5'de görüldüğü gibi yaklaşık $60-190^{\circ} \mathrm{C}$ aralığında erime fazı mevcuttur. Bu aralık, SA $\left(68-70^{\circ} \mathrm{C}\right)$ ve $\mathrm{PE}\left(190-210^{\circ} \mathrm{C}\right)$ 'in erime sıcaklığı aralığıdır ve tepkime 1 sı alandır.

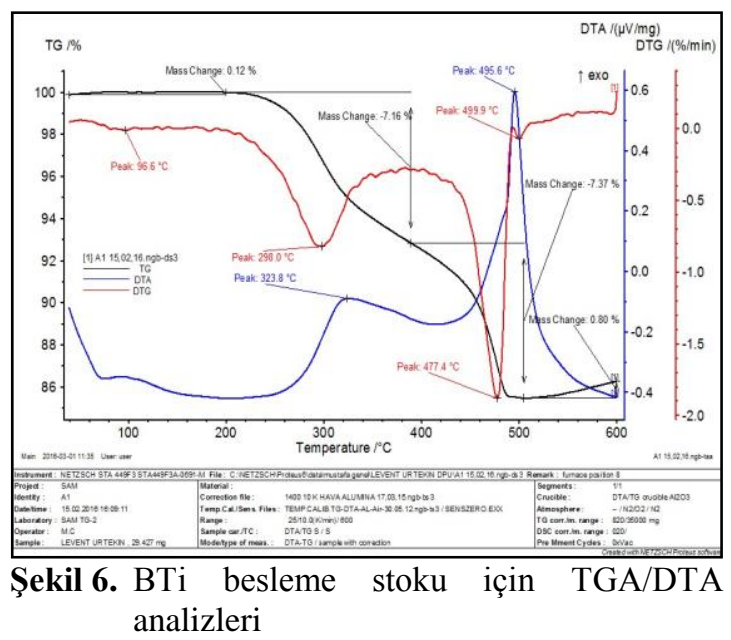

\subsection{Akış Simülasyon Sonuçları}

Autodesk Moldflow Simülasyon analizi ile kilitleme plaklarının akış özellikleri incelenmiştir. Şekil 7-10'da enjeksiyon parametrelerine ait sonuçlar verilmiştir.

Reoloji çalışmaları ile uzun zaman ve tecrübe gerektirerek belirlenen parametreler Moldflow simülasyon analizi ile daha kolay çözümlenebilmiştir.

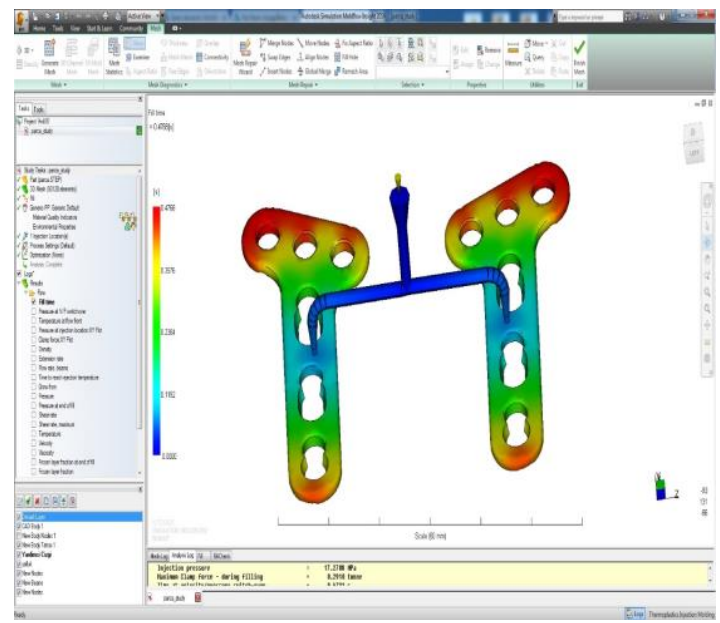

Şekil 7. Kalıp dolum süresi 


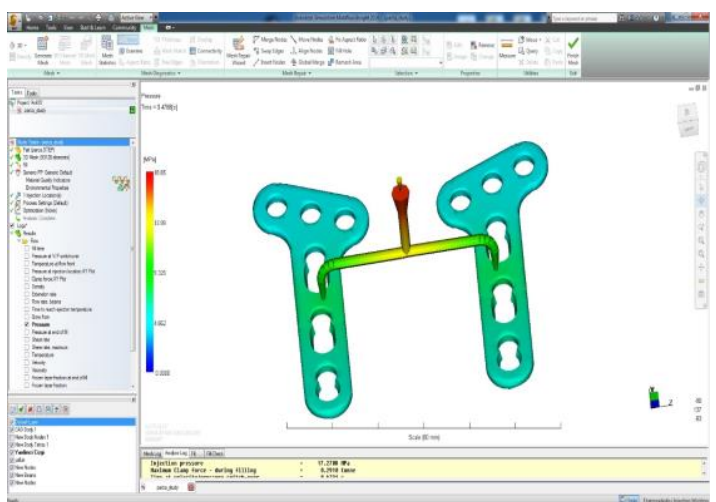

Şekil 8. Enjeksiyon basınç değişimi

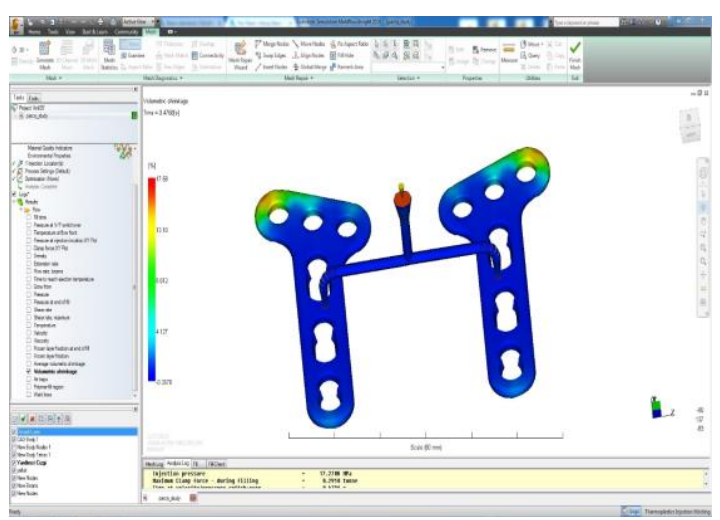

Şekil 9. Lineer çekme payı (\%)

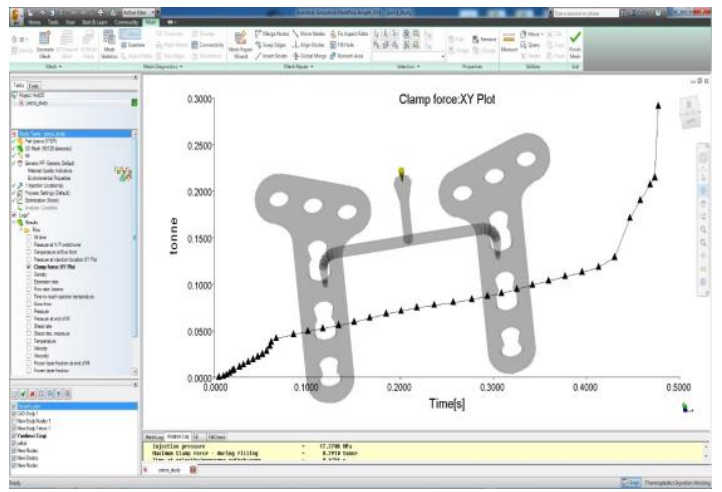

Şekil 10. Kalıp kapama kuvveti-zaman değişimi

Modflow analizleri neticesinde BTi besleme stoku için gerekli enjeksiyon parametreleri belirlenmiştir. TGA/DTA ve reoloji çalışmaları ile uyumlu olan simülasyon çalışmaları neticesinde toz enjeksiyon kalıplama ile $\mathrm{Ti}$ alaşımlı kilitleme plakalarının üretilebileceğine karar verilmiştir.

\section{SONUÇ}

BTİ besleme stoku üzerine k1lcal reometre ile deneyler yapılmış (Parafin wax/PE/SA) viskozite, erime akış indeksi ve sıcaklık davranışları toz enjeksiyon kalıplama ile uyumlu olduğu belirlenmiştir.

Moldflow simülasyon analizi ile reoloji çalışmalarının uyumu uzun zaman alan besleme stoku akış özelliklerinin belirlenme çalışmalarını azaltacak türdendir. Her bir karışı oranı için reoloji deneylerinin yapıldığ 1 ve kritik yükleme ile optimum yükleme arasında \%2-5 oranında bir değişim olduğu bilindiğine göre simülasyon analizinin bilimsel çalışmalara yardımcı olacă̆ görülmüştür.

\section{TEŞEKKÜR}

$\mathrm{Bu}$ çalışma Ahi Evran Üniversitesi MMF.E2.16. 008 No'lu BAP projesi tarafindan desteklenmiştir.

\section{KAYNAKLAR}

1. Mutsuddy, B.C., Ford, R.G., 1995. Ceramic Injection Molding, Chapman and Hall, UK.

2. Urtekin, L., Uslan, İ., Tuç, B., 2012. Investigation of Different Feedstock Rheologhy for Net-Shape Injection Molding of Steatite, Journal of the Faculty of Engineering and Architecture of Gazi University, 27, No 2, 333-341.

3. Sarıtaş, S., Türker, M., Durlu, N., 2007. Toz Metalurjisi ve Parçacıklı Malzeme İşlemleri 1. Baskı, Uyum Ajans, Ankara.

4. Urtekin, L., 2008. Toz Enjeksiyon Kalıplanmış Steatit Seramiklerin Özelliklerine Kalıplama ve Sinterleme Parametrelerinin Etkisinin Araştırılması, Gazi Üniversitesi Fen Bilimleri Enstitüsü, Doktora.

5. German, R.M., 2013. Progress in Titanium Metal Powder Injection Molding, Materials, 6, 3641-3662.

6. German, R.M., 1990. Powder Injection Molding, New Jersey, USA, 200-225. 
7. German, R.M., Bose, A., 1997. Injection Molding of Metals and Ceramics, Metal Powder Industries Federation, New Jersey, 10-35.

8. Morita, A.T., Toma, M.S., De Paoli, M.A., 2005. Low Cost Capillary Rheometer, Transfer Molding and Die-Drawing Module, Polymer Testing, 25: 197-202.

9. Motorcu, A.R., 2009. Nikel Esaslı Süper Alaşımların ve Titanyum Alaşımlarının İslenebilirliği, 1. Bölum: Sinterlenmis Karbur Takımların Performanslarının Değerlendirilmesi, Erciyes Üniversitesi Fen Bilimleri Enstitüsü Dergisi, 25(1-2); 302-330.

10.Zoya, Z.A., Krishnamurthy, R., 2000. The Performance of CBN Tools in the Machining of Titanium Alloys, Journal of Materials Processing Technology, 100; 80-86.

11. Rahman, M., Wang, Z.G., Wong, Y.S., 2006. A Review on High-Speed Machining of Titanium Alloys, JSME International Journal Series C, 49 (1); 11-19.

12. ASTM D1238, Standard Test Method for Melt Flow Rates of Thermoplastics by Extrusion Plastometer.

13. ASTM D3835, Standard Test Method for Determination of Properties of Polymeric Materials by Means of a Capillary Rheometer. 
